\title{
Mechanical Characterisation of Insulation Panels Based on Vegetable Typha Domingensis and Starch
}

\section{Henri Wilfried Hounkpatin ${ }^{1, *}$, Victorin Kouamy Chegnimonhan ${ }^{2}$, Clement Adeyemi Kouchade $^{1}$, Basile Bruno Kounouhewa ${ }^{1}$}

${ }^{1}$ Laboratory of Radiation Physics (LPR), University of Abomey-Calavi, Cotonou, Benin

${ }^{2}$ Thermics and Energy Laboratory of Nantes, Nantes, France

\section{Email address:}

orestahenrius@gmail.com (H. W. Hounkpatin), victorin.chegnimonhan@univ-nantes.fr (V. K. Chégnimonhan), ckouchade@yahoo.fr (C. A. Kouchade), kbbasile@gmail.com (B. B. Kounouhewa)

${ }^{*}$ Corresponding author

\section{To cite this article:}

Henri Wilfried Hounkpatin, Victorin Kouamy Chegnimonhan, Clement Adeyemi Kouchade, Basile Bruno Kounouhewa. Mechanical Characterisation of Insulation Panels Based on Vegetable Typha Domingensis and Starch. Science Journal of Energy Engineering. Vol. 8, No. 3, 2020, pp. 33-43. doi: 10.11648/j.sjee.20200803.11

Received: August 5, 2020; Accepted: August 27, 2020; Published: September 16, 2020

\begin{abstract}
The results show that the variation in the swelling rate of some samples analysed describes a sinusoid with values higher than those recommended by the AINSI A 208.11999 standard. The use of these panels in a dry environment is therefore strongly recommended. The Young's modulus of elasticity (YME) and the breaking Modulus of Rupture (MOR) of the composite materials are between 0.91 and $2.31 \mathrm{GPa}$ and 5.39 and $16.43 \mathrm{MPa}$. These values meet the 1999 ANSI 208.1 standard, which requires that the YEM and MOR of insulation boards in buildings be greater than or equal to $550 \mathrm{MPa}$ and $3 \mathrm{MPa}$, respectively. Deformation at break varies between 8.40 and $13.05 \mathrm{~mm}$. These values explain the non-ductile behaviour of these materials. Finally, the evolution of the mechanical properties of the material (Flexural Modulus of Elasticity (FME), MOR and deformation) as a function of the binder rate and the particle size distribution indicate that the presence of starch in the small particle sizes $(\leq$ $0.425 \mathrm{~mm}$ ) favours the increase in the rigidity of the material. The breaking strength of the material (small granulometry) is greater with starch proportions ranging from 10 to $15 \%$. The presence of the binder in the composite, whatever the granulometry, changes the behaviour of the material by increasing its deformation at breakage. With regard to flexural behaviour, typha particles with a particle size between $0.425 \mathrm{~mm}$ and $1.25 \mathrm{~mm}$ with a binder content of $10 \%$ to $15 \%$ are therefore more ductile. With these characteristics, the formulations M1 $(10 \%$ starch; $0.425 \mathrm{~mm})$ and M4 (15\% starch; $0.425 \mathrm{~mm})$ indicate the best mechanical properties.
\end{abstract}

Keywords: Typha Domingensis, Starch, Insulation, Mechanical Characterisation

\section{Introduction}

The control of indoor thermal comfort is important for the well-being of the occupants in the habitat. To achieve this objective, several solutions are possible, mainly the insulation of the roof and walls to improve the thermal environment in the habitat $[1,2]$. Frequently used insulating materials are of synthetic origin, but nowadays biosourced insulation of animal or vegetable origin is increasingly experienced in construction [3]. The focus is now on plant-based materials, because they have low carbon footprints, with a life cycle that can be adapted to that of buildings, and are above all sustainable materials.

Several studies have focused on determining the thermophysical and mechanical characteristics of these materials in order to better integrate them into buildings. Osseni et al. [4] have determined the thermal characteristics of coconut fibre-doped cement mortars using the asymmetric hot-plane method with a temperature measurement. The results showed that the thermal conductivity decreases by about $10 \%$ when the proportion (up to 3\%) and/or the length of the fibres increases, thus confirming the capacity of the fibres to provide thermal insulation [3]. Insulating panels made from agricultural residues have been the subject of several research studies and publications. For example, Younquist et al. [5] and Younquistet 
al. [6] have examined agricultural residues such as kenaf and cotton stalks that could be used in the manufacture of particleboard. Onuorah et al. [7] studied the potential of Bambusa vulgaris grown in southeastern Nigeria for the manufacture of wood-cement composite panels. The composite panels were manufactured at density levels of $1200 \mathrm{~kg} \cdot \mathrm{m}^{-3}$ and $800 \mathrm{~kg} . \mathrm{m}^{-3}$. The prepared composition was subjected to an initial pre-compression of $0.5 \mathrm{~N} . \mathrm{mm}^{-2}$ and a final consolidation of $1.4 \mathrm{~N} . \mathrm{mm}^{-2}$ preserved for 24 hours. The panels were sampled and tested after 28 days for modulus of rupture (MOR) and modulus of elasticity (FME) in bending and for water absorption (WA) and thickness swelling (TS) due to a 24-hour water soak. Properties ranged from a minimum of 25 to 75.45 N.mm ${ }^{-2}$ for MOR, 4128 to 15.065 N.mm ${ }^{-2}$ for FME, 15.01 to $36.11 \%$ for WA and 3.04 to $12.72 \%$ for TS. These results meet the minimum ownership requirements of the American National Standard Institute 208-2-1994 and 208-1-1993, the British Standard (BS 5669, 1979) and the Malaysia Standard (MS 934, 1984). Nenonone [8], follow the same direction by studying the mechanical properties of kenaf particleboard with tanning extracts from P. biglobosa pods, S. caudatum leaf sheath and P. dulce bark. The results of this study show that the panels obtained have a low density with values ranging from 0.484 to 0.527 g.cm ${ }^{-3}$. The mechanical properties of $80 \%$ of the manufactured panels give values of 600 to $1300 \mathrm{MPa}$ for flexural modulus of elasticity (MEF), 5 to $11 \mathrm{MPa}$ for flexural strength properties (MOR) and 0.11 to $0.58 \mathrm{MPa}$ for internal cohesion (IB). These results meet the requirements of the American standard ANSI 208.1, 1999 (550 MPa, $3 \mathrm{MPa}$ and 0.1 MPa for FME, MOR and IB respectively). Soulama et al. [9] optimized the processing and physical properties of particleboard from cotton (Gossipium hirsutum) and kenaf (Hibiscus cannabinus L.). They found that the use of UF resin as a binder gives a density of $660.225 \mathrm{MPa}$ for the debarked cotton stemboard and 639.37 MPa for the kenaf stemboard. Similarly, the flexural modulus of elasticity or Young's modulus FME are 1757.49 MPa and 2230.5 MPa respectively for the cotton and kenaf stem board. These values are higher than those recommended by ANSI A208.1-1999 at 550 MPa.
The Modulus of Rupture (MOR) is 15.52 MPa and 19.90 MPa for cotton and kenaf stemboard at $10 \mathrm{MPa}$, respectively, which is recommended by ANSI A 208.1-1999. Soviwadan and Assogba [10] go in the same direction by valorizing the carpentry residues which are the sawdust of kapok tree with the tannic powders of nere pod husk (Parkiabiglobosa) by the manufacture of particleboard. The bending tests made it possible to calculate the modulus of elasticity (FME) ranging from $7.840 \mathrm{MPa}$ to $19.500 \mathrm{MPa}$ and the modulus of rupture (MOR) ranging from $6.84 \mathrm{MPa}$ to $12.14 \mathrm{MPa}$. The tensile modulus leads to the determination of the Young's modulus, which varies from $6.660 \mathrm{MPa}$ to $19.869 \mathrm{MPa}$, the modulus of rupture (MOT), which varies from 19.16 $\mathrm{MPa}$ to $28.36 \mathrm{MPa}$, and the internal cohesion (IB), which varies from 6,660 MPa to $19,869 \mathrm{MPa}$, the modulus of elasticity (MEF), which varies from 7.840 $\mathrm{MPa}$ to $19.500 \mathrm{MPa}$, and the modulus of rupture (MOR), which varies from $6.84 \mathrm{MPa}$ to $12.14 \mathrm{MPa}$.

\section{Material and Methods}

\subsection{Materials}

The particle fibres used in this study were derived from crushed, dried and heat-pressed typha stems as reported in the works of [11]. Cassava starch was used as a binder. In addition to these two elements, distilled water was used. The tests were carried out with laboratory glassware, an oven, a grain mill, a thermostat, a thermo-pressed mould, an electronic balance with a sensitivity of $0.1 \mathrm{~g}$, a hydraulic press on which the mould presented in [11] was mounted, and a mechanical testing machine.

In this study, the samples were subjected to 4-point bending tests carried out at the Institute of Mechanical and Material Thermics of Reims University in France (ITheMM) to evaluate mechanical properties such as modulus of rupture in FME bending, modulus of rupture in MOR bending, $\mathrm{Y}$ deflection at break and force-displacement behaviour of the materials in bending.

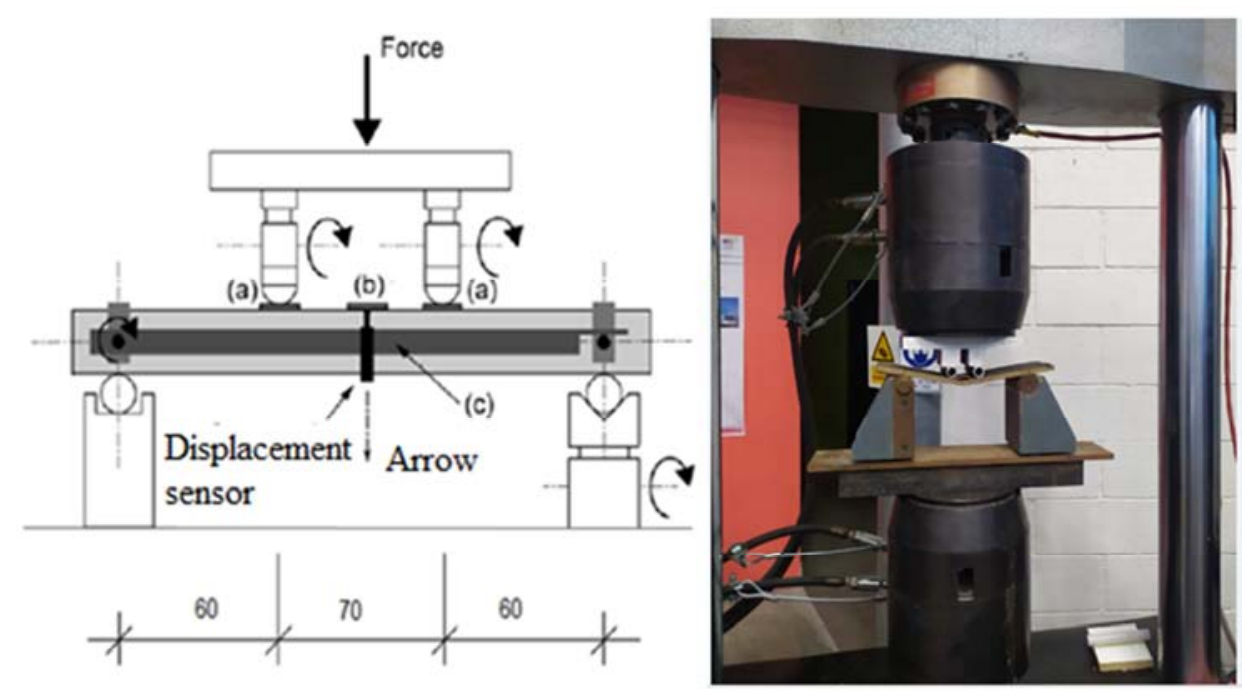

Figure 1. Mechanical characterisation test bench. 
Four-point bending consists of determining the deformation of a rectangular plate (specimen) resting on two simple supports by means of a force applied at two points located at equal distance from the supports and moving at constant speed The dimensions of the plate are $270 \mathrm{~mm}$ x $50 \mathrm{~mm}$. The four-point bending test is carried out using a machine controlled in displacement $(50 \mathrm{~mm})$ or in force by a hydraulic cylinder with a maximum load capacity of $250 \mathrm{kN}$ (Figure 1).

The specimen is arranged so as to subject the tamper face. Two inductive displacement transducers are placed at mid-span on either side of the specimen and are attached to it by a measuring frame (c) fixed in line with the supports, at mid-height of the specimen. The displacement shall be measured in relation to a tell-tale attached to the test piece (b).

The span between the axes of the supports is $190 \mathrm{~mm}$. The bending forces are distributed uniformly by means of deformable plates (a) placed under the points of application of the displacements. It is subject to ISO 178, ASTM D790,

(a)
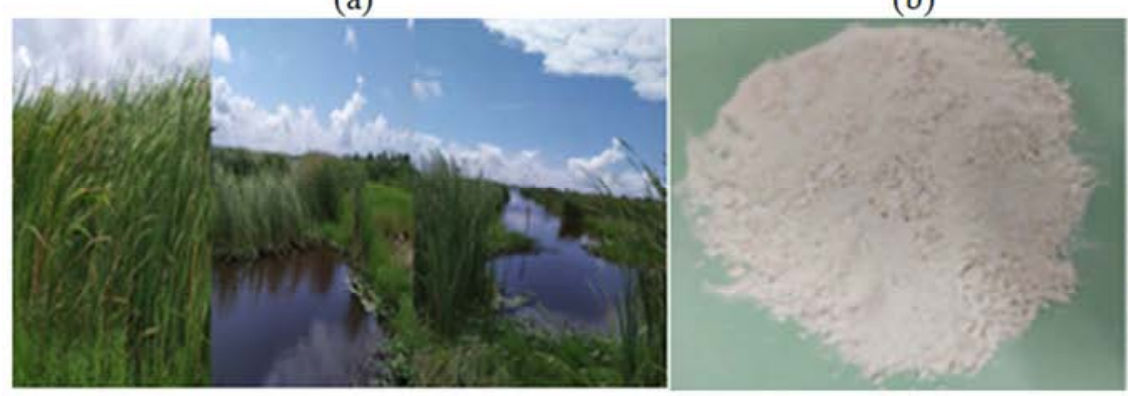

\subsection{Methods}

(b)

D5934 and D5943. The device used in this study complies with standard NF EN 12390-2 and is located at the Institute of Mechanical and Material Thermics, EA: 7548/MA-civil engineering, University of Reims in Champagne Ardennes.

\subsubsection{Raw Material Synthesis Method}

The approach to aggregating the raw material was presented in the works of [11]. Typha stems were harvested at maturity and dried for 2 weeks in the sun. After drying, the stems were cut into small pieces of about $1 \mathrm{~cm} \times 2 \mathrm{~cm}$. The granules are then stored in an oven at a temperature of $105^{\circ} \mathrm{C}$ for 24 hours and then crushed into fine to medium particles using a Vicking type knife mill. After drying the starch in the sun, the powder obtained was placed in the oven (Figure 2b) together with the fibres. Figure 2 gives an overview of the typha in its natural living environment (Figure 2a) and after the grinding stage (Figure 2c).

(c)

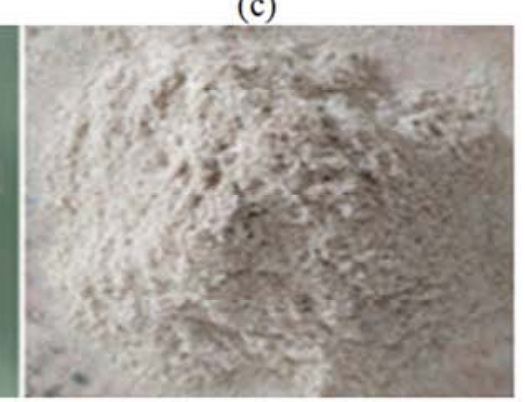

Figure 2. a) Typha domengensis image b) Photo of starch and c) Particles of typha [11].

\subsubsection{Physical Characterization Method}

The water content has been evaluated according to NF P 94-050 and the water absorption rate according to NF $P$ 18-555. The analysis of the granulometric distribution of the fibres was evaluated according to standard NF P94-056 and presented in the works of [11]. These results are summarized in section 2.2.3.

\subsubsection{Method of Sample Preparation}

The material samples were taken using the thermo compression process. After drying and grinding, typha fibres, starch and distilled water in defined proportions were mixed. This mixture was moulded by thermo compression at a temperature of $105 \pm 1^{\circ} \mathrm{C}$ under a pressure of $2.2 \mathrm{MPa}$ for 20 minutes in order to produce the typha-starch panels. The process presented in the works of [11] can be summarized by the diagram in Figure 3. The percentage of starch varies between 0 and $20 \%$. The samples were made according to three classes of granulometry namely:

Classe A: [0; 0,425 mm], Classe B:] 0,425 mm; 1,25 mm]

Classe C: [1,25 mm; 1,70 mm].

The designations and different compositions are presented in Table 1 and Figure 4 shows piles of manufactured panels.

\subsubsection{Thickness Swelling Rate}

In accordance with EN 317, the thickness swelling (TS:
Thickness Swelling) of each particle panel is determined by measuring the thickness of $6 \times 50$ specimens before and after immersion in water for 2 hoursor 24 hours. The thickness swelling rate of each specimen is calculated according to the formula below as mentioned in the works of [12].

$$
T S(\%)=\frac{\left(t_{2}-t_{1}\right)}{t_{1}} \times 100
$$

where $t_{2}$ : thickness of the specimen before immersion ( $\mathrm{mm}$ ), $t_{1}$ : thickness of the specimen after immersion (mm).

\subsubsection{Mechanical Characterization Method}

The characteristics MEF (Modulus of elasticity in bending) and MOR (Modulus of Rupture) are calculated with equations (2) and (3) [13]:

$$
\begin{gathered}
\mathrm{MEF}=\frac{\mathrm{FL}^{3}\left(\frac{3 a}{\mathrm{~L}}-\frac{4 \mathrm{a}^{3}}{\mathrm{~L}^{3}}\right)}{2 b h^{3} \mathrm{y}} \\
\mathrm{MOR}=\frac{6 \mathrm{~F}_{\mathrm{r}} \mathrm{a}}{b \mathrm{~h}^{2}}
\end{gathered}
$$

$\mathrm{F}$ is the force exerted through each plate $(\mathrm{N}), \mathrm{L}$ is the distance between the supports ( $\mathrm{mm}$ ) and is $190 \mathrm{~mm}$, a is the 
distance between a force and the end of the test piece ( $\mathrm{mm}), \mathrm{b}$ is the width of the test $(\mathrm{mm}), \mathrm{h}$ is the thickness of the test piece $(\mathrm{mm}), \mathrm{y}$ is the deformation at put through $(\mathrm{x}=\mathrm{L} / 2)(\mathrm{mm})$. The

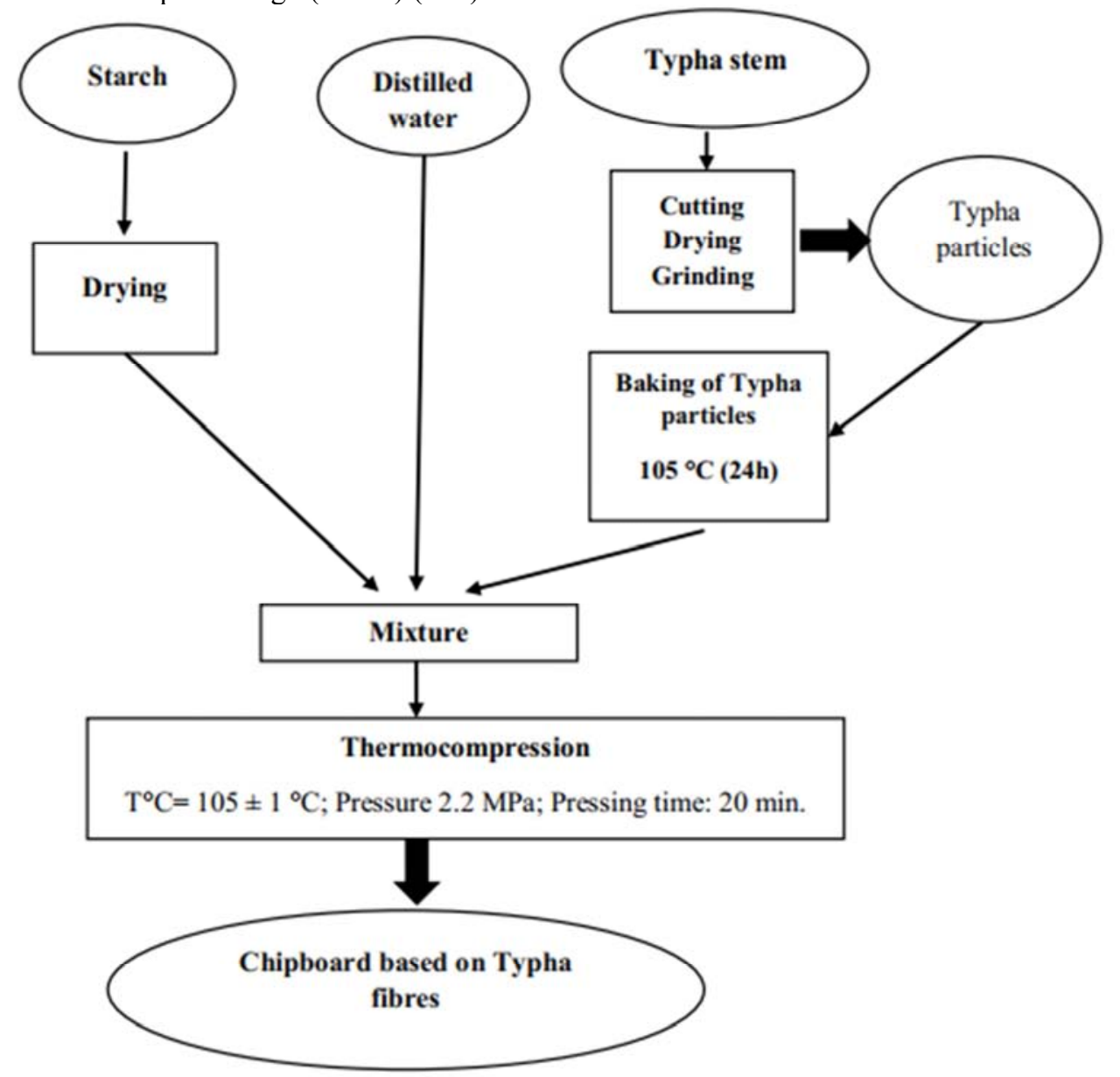

Figure 3. Implementation diagram for the formulation of typha-starch panels.
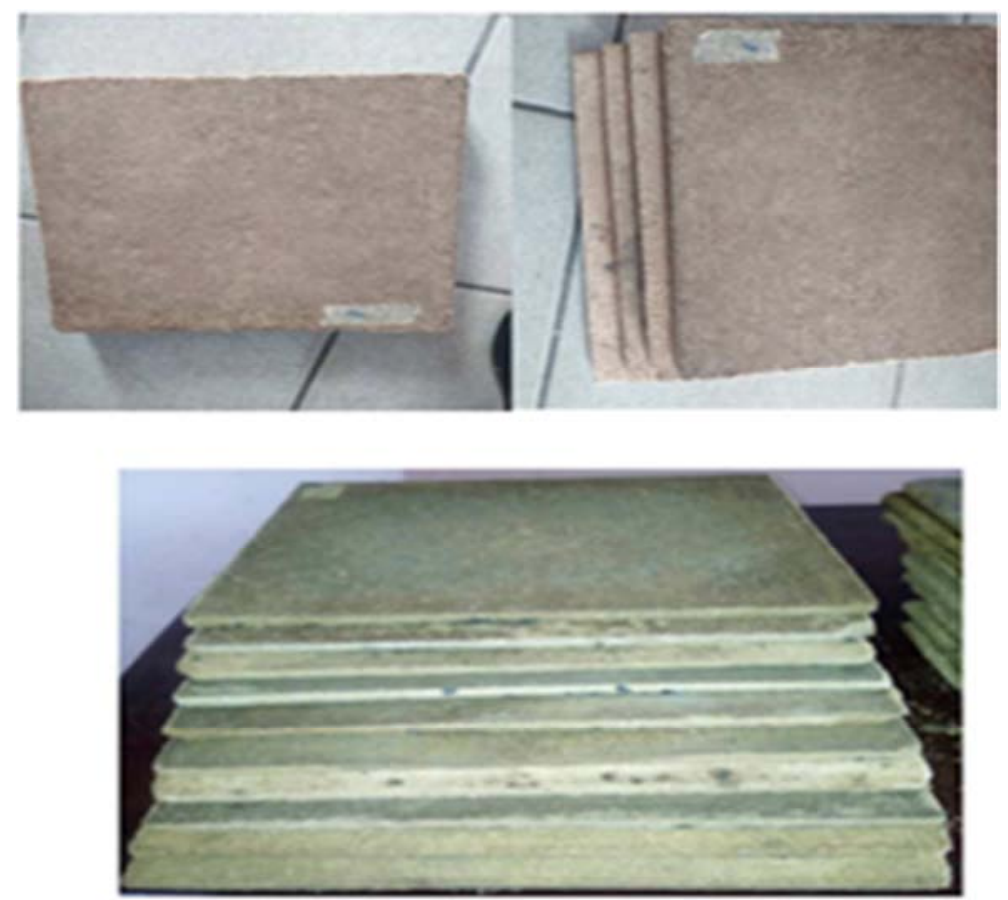

Figure 4. Thermo-compressed particle panels [11]. characteristics of the test piece are as follows: $\mathrm{a}=60 \mathrm{~mm}, \mathrm{~b}=50$ $\mathrm{mm}$ and $\mathrm{h}$ varies from $0.80 \mathrm{~cm}$ to $1.20 \mathrm{~cm}$. 
Table 1. Sample compositions.

\begin{tabular}{llll}
\hline Designations & $\begin{array}{l}\text { Binder } \\
\text { content } \%\end{array}$ & $\begin{array}{l}\text { Fibre } \\
\text { content } \%\end{array}$ & Granulometry \\
\hline G2 & 0 & 100 & A \\
G6 & 0 & 100 & B \\
G3 & 0 & 100 & C \\
M1 & 10 & 90 & A \\
M3 & 10 & 90 & B \\
L7 & 10 & 90 & C \\
M4 & 15 & 85 & A \\
M6 & 15 & 85 & B \\
L8 & 15 & 85 & C \\
M7 & 20 & 80 & A \\
M9 & 20 & 80 & B \\
L9 & 20 & 80 & C \\
\hline
\end{tabular}

\section{Results and Discussions}

\subsection{Change in Swelling Rate}

In Table 2, the swelling rates TS of a few samples of the insulation boards after $2 \mathrm{~h}$ and $24 \mathrm{~h}$ immersion in water are presented.

Table 2. Swelling rate results.

\begin{tabular}{llll}
\hline Binder (starch) content & Sample & TS (\%) (2 h) & TS (\%) (24 h) \\
\hline $10 \%(0.250 \mathrm{~mm})$ & L1 & 71.26 & 107.05 \\
$10 \%(1.70 \mathrm{~mm})$ & L7 & 113.82 & 124.76 \\
$20 \%(0.250 \mathrm{~mm})$ & L3 & 61.43 & 104.19 \\
$15 \%(0.250 \mathrm{~mm})$ & L2 & 70.05 & 106.28 \\
$20 \%(0.125 \mathrm{~mm}$ & M9 & 62.34 & 79.42 \\
$10 \%(0.425 \mathrm{~mm})$ & M1 & 73.33 & 133.09 \\
\hline
\end{tabular}

The results indicate that the swelling rate varies from $61.43 \%$ (L3 sample) to $113.82 \%$ (L7 sample) in $2 \mathrm{~h}$ and from $79.42 \%$ (M9) to $133.09 \%$ (M1) in $24 \mathrm{~h}$. This variation describes a sinusoid with a best estimate of the swelling rate for the M9 composite $(20 \% ; 0.125 \mathrm{~mm})$ and a poor estimate for the $\mathrm{L} 7$ composite $(10 \% ; 1.70 \mathrm{~mm})$. Comparing these values with those specified by the AINSI A 208.1 1999 standard, which recommends a percentage of $8 \%$ after $2 \mathrm{~h}$ of water immersion and $15 \%$ in $24 \mathrm{~h}$, it can be seen that the rates obtained in this study are much higher. Therefore, the use of these panels in dry air environments is strongly recommended. A conditioning or treatment against the untimely absorption of water could be the subject of future investigations in order to widen the use of these panels in wet areas. These results are confirmed by the works of [14-16]. In addition, the values of the swelling rate of the typha-starch panels are lower than those obtained by [15] for Kenaf and cotton stem panels and [14] for Kapokier sawdust particleboard with the tanniferous powder of the Nere pod pod husk. The values indicated by these authors are respectively estimated at $168 \%$ to $180 \%$, $109.872 \%$ to $165.894 \%$.

\subsection{Four-Point Bending Tests}

The bending tests carried out determined the bending modulus of elasticity MEF, the breaking strength in bending
MOR, the maximum deformation in bending $\mathrm{Y}$ and the force-displacement behaviour of the insulation panels. The values of MEF, MOR and Y obtained are displayed in Table 3.

The Young's modulus and the modulus of rupture of agro-materials vary respectively between 910 and $2310 \mathrm{MPa}$ then 5.39 and 16.43 MPa. The different FME and ORM values obtained comply with the 1999 ANSI 208.1 standard according to which the FME and ORM of insulation boards in buildings must be greater than or equal to $550 \mathrm{MPa}$ and $3 \mathrm{MPa}$ respectively. Deflection at break is low and varies between 8.40 and $13.05 \mathrm{~mm}$. These values explain the brittle behaviour of these materials. The works of [8] on the mechanical properties of kenaf rod particles estimates the modulus of elasticity in bending between 600 and $1300 \mathrm{MPa}$ and the modulus of bending stress between 5 and $11 \mathrm{MPa}$. These values are well below the bending elasticity and bending fracture characteristics obtained in this study. Drovou et al. [14] have valorized the carpentry residues which are the sawdust of kapok tree with the tannic powders of nere pod pods (Parkiabiglobosa), through the manufacture of particleboard in order to seek palliatives to the environmental problems posed by sawdust and the use of conventional binders. The mechanical and physical properties of these panels made by means of the three-point bending test were determined. The bending test made it possible to calculate the modulus of elasticity varying between $7840 \mathrm{MPa}$ and 19500 $\mathrm{MPa}$ and the modulus of rupture varying between $6.84 \mathrm{MPa}$ and $12.14 \mathrm{MPa}$. It can therefore be seen that the elasticity of these kenaf-based panels is greater than that obtained with typha-starch panels, but their modulus of rupture is lower. Soulama et al. [9] identified the optimal values of the processing parameters for particleboard with kenaf and cotton stems using a natural binder (bone glue) and developed two types of panels with optimized processing parameters. The mechanical characteristics of the processed panels are then determined for applications in interior thermal insulation. The flexural modulus of elasticity or Young's modulus of elasticity (FME) was evaluated at $1757.49 \mathrm{MPa}$ and 2230.5 $\mathrm{MPa}$ respectively for the cotton and kenaf rod panel. These values are also higher than those recommended by ANSI A208.1-1999, which is a minimum of $550 \mathrm{MPa}$. Similar results are also obtained by [17] In addition, the Modulus of Rupture (MOR) for these two types of panels are estimated at 15.52 $\mathrm{MPa}$ and $19.90 \mathrm{MPa}$ for the cotton rod panel and the kenaf panel at $10 \mathrm{MPa}$, respectively, which is recommended by ANSI A 208.1-1999. Niang [18] studied the mechanical properties of an agro-material based on clay soil and aggregates of typha Australis developed in order to assess the influence of the morphology and quantity of fibres on the behaviour of the material. The results obtained from the 4-point bending tests indicate that the maximum allowable bending load ranges from $205.667 \pm 46.490$ to $965.350 \pm 56.580$ $\mathrm{MPa}$ for the formulations tested. The maximum bending strength varies from $0.281 \pm 0.016$ to $0.067 \pm 0.009 \mathrm{MPa}$. These different results therefore confirm the values obtained in this study for the modulus of elasticity and the modulus of rupture 
resistance.

Table 3. MEF, MOR and Y values.

\begin{tabular}{lllllllll}
\hline Sample & Starch Rate $\%$ & Granulometry & MEF (GPa) & $\Delta$ MEF & MOR (MPa) & $\Delta$ MOR & Y (mm) & $\Delta$ Y \\
\hline G2 & 0 & A & 1.57 & 0.67 & 9.96 & 4.14 & 12.38 & 1.24 \\
G6 & 0 & B & 1.33 & 0.52 & 7.20 & 2.32 & 9.27 & 0.67 \\
G3 & 0 & C & 1.27 & 0.99 & 5.39 & 4.57 & 8.40 & 4.19 \\
M1 & 10 & A & 2.15 & 0.19 & 13.12 & 2.80 & 9.81 & 0.52 \\
M3 & 10 & B & 1.57 & 0.30 & 12.35 & 3.49 & 10.08 & 1.87 \\
L7 & 10 & C & 1.31 & 0.57 & 5.84 & 2.42 & 10.61 & 2.49 \\
M4 & 15 & A & 2.23 & 0.16 & 16.43 & 1.56 & 10.42 & 1.94 \\
M6 & 15 & B & 1.43 & 0.41 & 11.92 & 0.80 & 12.43 & 1.84 \\
L8 & 15 & C & 1.03 & 0.61 & 6.90 & 3.62 & 13.05 & 1.70 \\
M7 & 20 & A & 2.31 & 0.47 & 13.34 & 3.97 & 8.65 & 2.05 \\
M9 & 20 & B & 1.84 & 0.45 & 11.81 & 1.93 & 12.00 & 2.31 \\
L9 & 20 & C & 0.91 & 0.29 & 8.65 & 3.83 & 12.43 & 1.74 \\
\hline
\end{tabular}

\subsection{Evolution of Young's Modulus as a Function of Starch Content}

Figure 5 shows the evolution of the MEF for each granular class as a function of starch content. The MEF is found to be an increasing function of the binder content and varies from 1.52 to $2.31 \mathrm{GPa}$ for granular class A. For granular class B, the MEF increases from $1.30 \mathrm{GPa}(0 \%$ binder $)$ to $1.50 \mathrm{GPa}$ ( $10 \%$ binder). For the $15 \%$ binder content, it decreases to $1.45 \mathrm{GPa}$ and then increases to $1.86 \mathrm{GPa}$ for the $20 \%$ binder content. For granular class $\mathrm{C}$, the $\mathrm{MEF}$ is an increasing function of the binder content from $0 \%$ to $15 \%$. It varies from $0.90 \mathrm{GPa}$ to $1.3 \mathrm{GPa}$. For the binder content of $20 \%$ there is a slight decrease with an estimated value of $1.29 \mathrm{GPa}$. Therefore, depending on the granular class, the MEF evolves differently according to the binder rate. When the granulometry of the typha particles is smaller, the presence of the binder favours an increase in the rigidity of the material. This is not always the case with larger grain sizes. These different results are corroborated by the work of Niang [18] on the mechanical characterization of an agromaterial based on clay soil and Australis typha aggregates, which states that the increase in binder content significantly improves the flexural strength due to its greater rigidity.

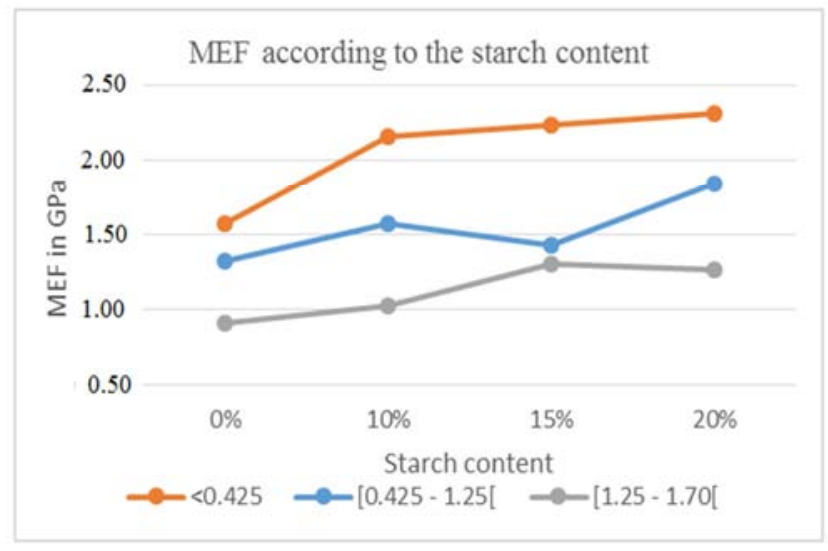

Figure 5. Variation of Young's modulus as a function of starch content.

\subsection{Evolution of Breaking Strength as a Function of Starch Content}

Figure 6 shows the evolution of the ORM for each granular class as a function of the binder content.

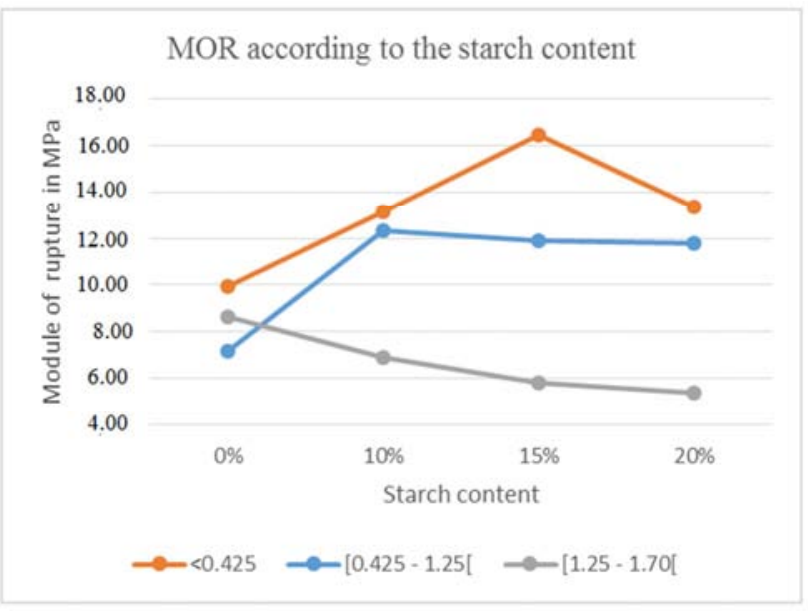

Figure 6. Variation of the breaking strength of the material as a function of starch content.

This variation is not uniform from one grain size class to another. However, between $15 \%$ and $20 \%$ binder, we notice that the ORM decreases from 16.1 MPa to $12.8 \mathrm{MPa}$ for granular class $\mathrm{A}$, from $12 \mathrm{MPa}$ to $11.9 \mathrm{MPa}$ for class $\mathrm{B}$ and from $6 \mathrm{MPa}$ to $5.7 \mathrm{MPa}$ for class $\mathrm{C}$. From $0 \%$ to $15 \%$ binder for class A, the MOR is an increasing function of the binder content and varies from $10 \mathrm{MPa}$ to $16.1 \mathrm{MPa}$. From $0 \%$ to $10 \%$ binder for class $\mathrm{B}$, the breaking strength of the material evolves from 7 $\mathrm{MPa}$ to $12.1 \mathrm{MPa}$. For granular class $\mathrm{C}$, this breaking strength is a decreasing function of the binder content. It decreases from 8.7 $\mathrm{MPa}$ to $5.7 \mathrm{MPa}$. In sum, the breaking strength of the material is more important for small granulometries containing binder (starch proportions ranging from 10 to $15 \%$ in the case of this study). These results are confirmed by the works of $[19,20]$, who consider that the finest and most fibrous particles that are well dispersed lead to better mechanical properties. Similarly, Soulama et al. [9] obtained similar results with binder contents ranging from $5 \%$ to $12.5 \%$, where an increase in MEF and 
MOR is observed, reaching respectively values of $1950.78 \mathrm{MPa}$ and 17.01 MPa for kenaf and cotton stem boards. When the binder content exceeds $12.5 \%$, there is a decrease in MEF and MOR. The authors therefore conclude that the best mechanical properties are obtained with the binder content of $10 \%$ and $12.5 \%$. Nonenene et al. [8] in their work on the mechanical characterization of kenaf stem-based panels mixed with bone glue estimated that the effects of mixing bone glue and extracts of tanniferous plant organs on the flexural strength characteristics of the panels are the most remarkable. For all binders consisting of $50 \%$ bone glue and $50 \%$ organ extract, the modulus of elasticity (MEF) values increased. The flexural fracture resistances have all practically doubled, compared to the same binder without bone glue, and even more than tripled in the case of the leaf sheath extract of $S$. caudatum (MOR: 2.4 to $8 \mathrm{MPa}$ ). These results also confirm the influence of the presence of binder in the fine particles to obtain better mechanical properties (modulus of elasticity in flexion and breaking strength).

\subsection{Evolution of Strain at Break as a Function of Starch Content}

Figure 7 shows the variation in the strain at break of the material as a function of the starch content.

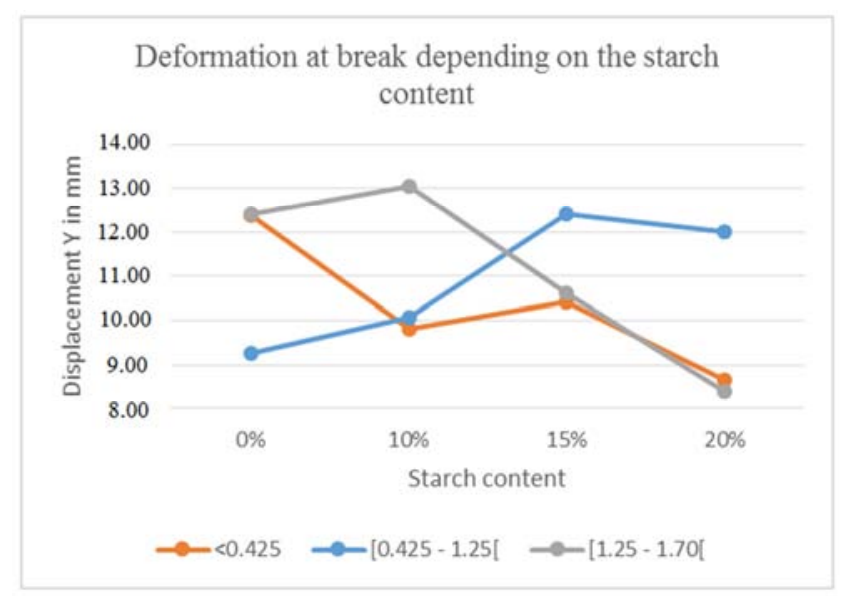

Figure 7. Variation of deformation at material rupture as a function of starch content.

Typha-starch-based insulation panels generally have a fracture strain of between $8.40 \mathrm{~mm}$ and $13.65 \mathrm{~mm}$. This characteristic of material brittleness is not uniform for all three granular classes depending on the binder content. Formulations containing starch proportions ranging from $10 \%$ to $15 \%$ or $20 \%$ in places for granulometries greater than 0.425 $\mathrm{mm}$ (coarse particles) have a displacement that can induce higher deformation at breakage. When the particles are finer, it is the binder-free formulations that have a higher strain-to-break displacement $(12.50 \mathrm{~mm})$.

\subsection{Mechanical Behaviour in Bending as a Function of Starch Content}

In Figure 8, the mechanical flexural behaviour of the material is shown for each starch content. Figures 8a, 8b, 8c show the variations in the force-displacement behaviour of the insulation panels. In can be noted that for each granular class, the behaviours of the different formulations of panels are similar regardless of the starch content, but the breaking strength of the material and the induced displacement differ. The materials in general do not show ductile behaviour, the elastic zone extends to the maximum strength for the four binder rates. Indeed, the load-displacement curves indicate three distinct stages during the test. A linear portion that corresponds to the elastic behaviour of the composite. It represents the stiffness of the undamaged composite. Then the second part (non-linear plastic behaviour) which characterises a reduction in the tangent elastoplastic modulus. The third step represents the beginning of cracking at the bottom of the composite panel. From a certain maximum value and following a given displacement, the force decreases to reach minimum values depending on the proportion of binder after the panels have broken. For grain sizes between $0 \mathrm{~mm}$ and $0.425 \mathrm{~mm}$, panels with a binder content of $15 \%$ require a higher load displacement $(12.5 \mathrm{~mm})$ before they break, unlike large grain sizes $(1.25$ $\mathrm{mm}$ to $1.70 \mathrm{~mm}$ ) where the displacement is between $7 \mathrm{~mm}$ and $9 \mathrm{~mm}$. Fine-particle panels with a $15 \%$ binder content therefore have better mechanical properties in terms of force-displacement behaviour. This behaviour of the composite under load is consistent with the works of [21-24] who respectively investigated the mechanical characteristics of concrete containing wood chips as aggregates, jute-epoxy composite, carbon fibre reinforced epoxy, glass micro-balloon reinforced composites, fibre reinforced carbon epoxy using quasi-isotropic orientation.

\subsection{Evolution of Young's Modulus as a Function of Granular Class}

Figure 9 shows for each binder ratio, the variation of Young's modulus in bending as a function of the granular class. It can be seen that for all four binder ratios, the MEF decreases with increasing particle size. The flexural modulus of elasticity thus decreases from $2.3 \mathrm{GPa}$ to $0.90 \mathrm{GPa}$ regardless of the binder ratio and formulation type. The larger the particle size, the lower the MEF. Particle size therefore has an important influence on the MEF of materials.

On the other hand, for $0 \%$ binder, there is not a large variation in MEF depending on the particle size. These results are consistent with the works of [19-20].

\subsection{Deformation at Break as a Function of Granular Class}

In Figure 10, the evolution of strain at break as a function of typha particle size for each binder ratio is presented. For proportions ranging from $10 \%$ to $20 \%$ binder, the deflection at break increases with particle size from $8.5 \mathrm{~mm}$ to $13 \mathrm{~mm}$ regardless of the grain size, while it decreases from $12.4 \mathrm{~mm}$ to $8.3 \mathrm{~mm}$ for the $0 \%$ binder proportion. The presence of binder therefore changes the behaviour of the material by increasing its deformation at break depending on the grain size class. 


\subsection{Mechanical Bending Behaviour as a Function of Granule Class}

Figures $11 \mathrm{a}, 11 \mathrm{~b}, 11 \mathrm{c}$ and $11 \mathrm{~d}$ show the variations in panel displacement-forces as a function of grain class for each binder rate.

It can be seen that for panels without binder $(0 \%)$, the three granular classes show the same bending behaviour. However, for the others, there is a remarkable difference in the mechanical behaviour in bending on the ductility or brittleness of the panels. Typha particles with a grain size between 0.425

(a)

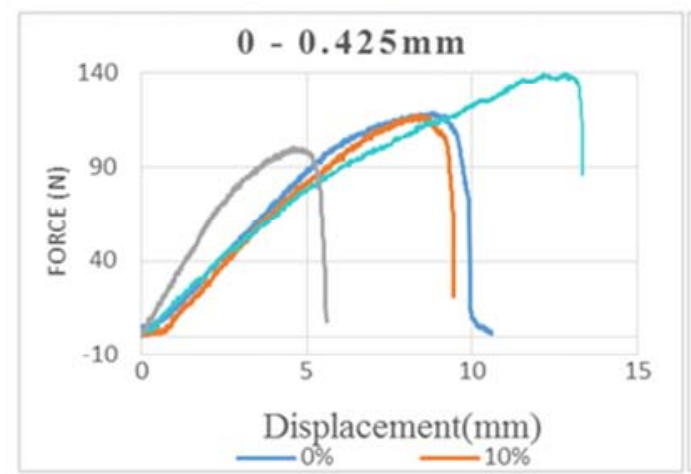

$\mathrm{mm}$ and $1.25 \mathrm{~mm}$ with a binder content of $10 \%$ to $15 \%$ require a higher pre-breakage displacement when subjected to a load. They are therefore more ductile than other formulations.

In short, the presence of matrix (binder) in the material ensures the connection of the reinforcing elements (typha), plays the role of protection, stress transmission and limitation of crack propagation and significantly influences the mechanical properties of the particleboard (rigidity, resistance to transverse stress, shear stress, inter laminar stress, fatigue behaviour and compressive strength) as indicated in the works of [25].

(b)

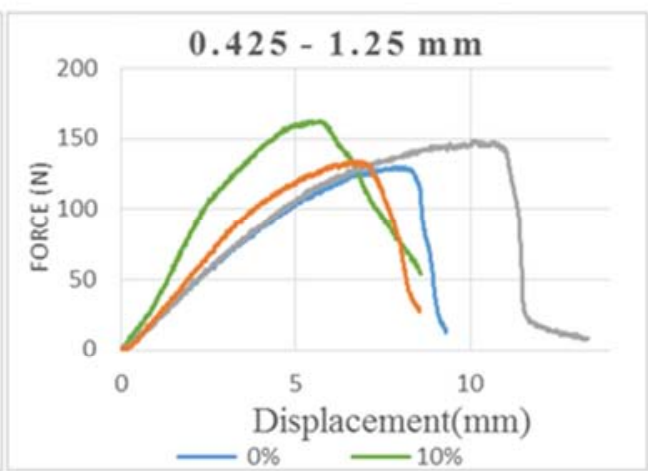

(c)

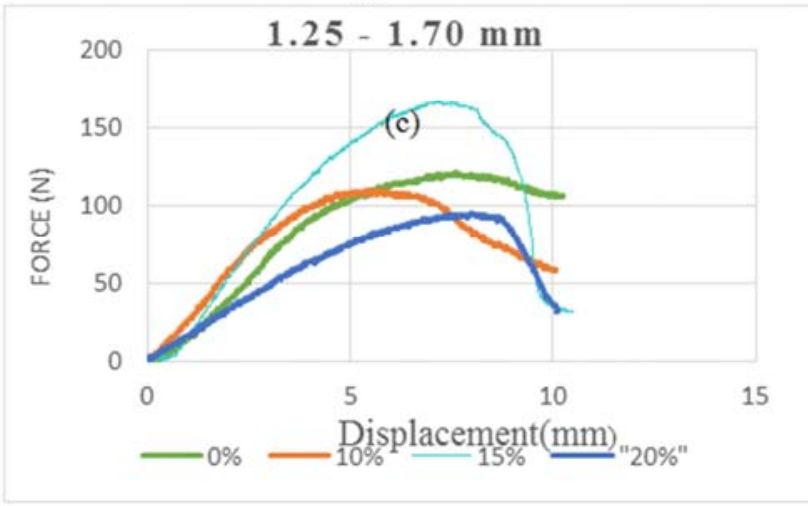

Figure 8. Mechanical bending behaviour as a function of starch content.

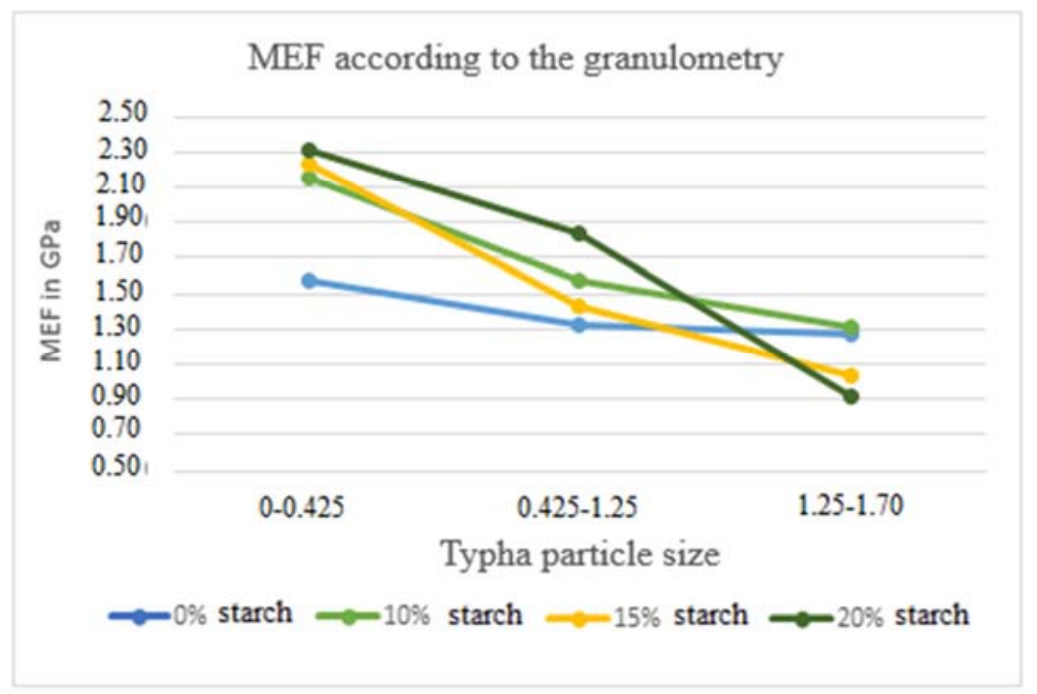

Figure 9. Variation of Young's modulus in bending as a function of granular class. 


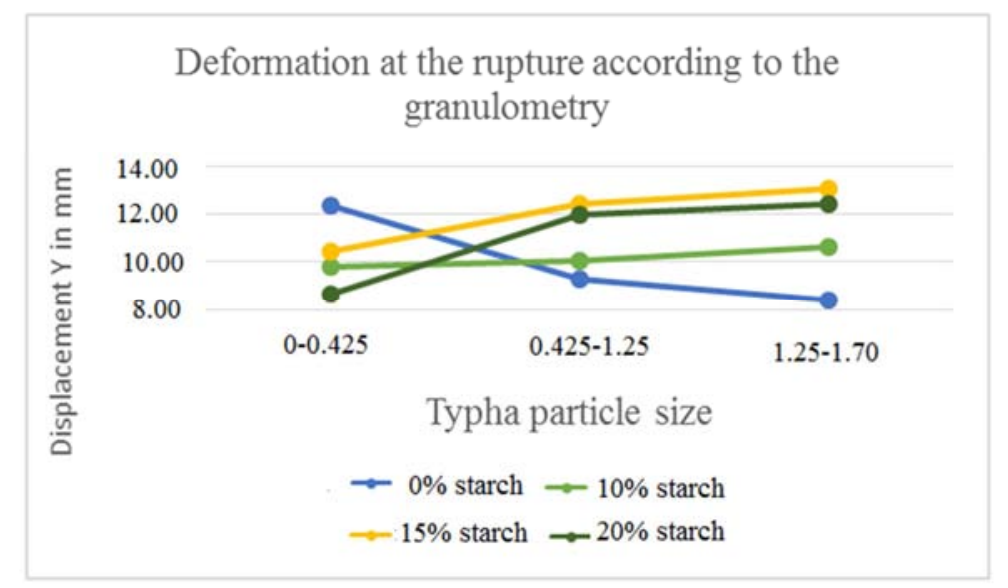

Figure 10. Variation of deformation at break of the material as a function of granular class.

(a)

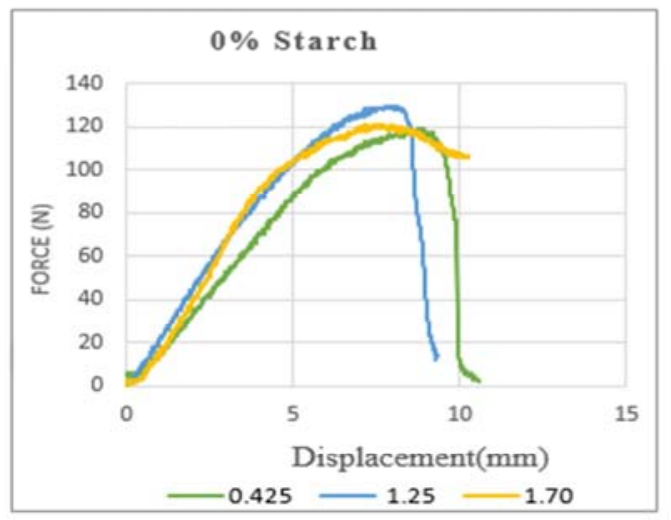

(c)

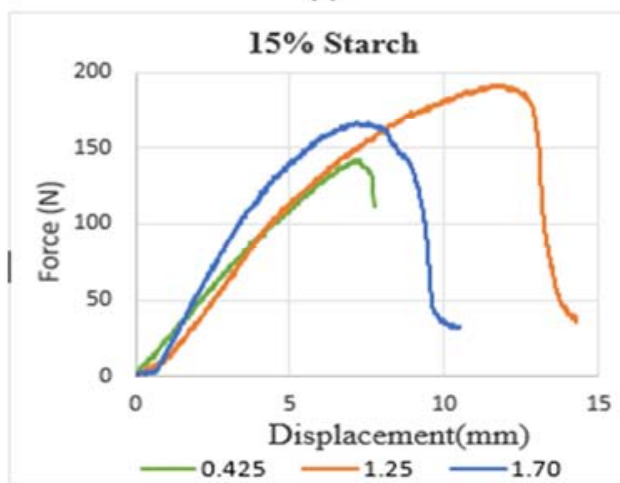

(b)

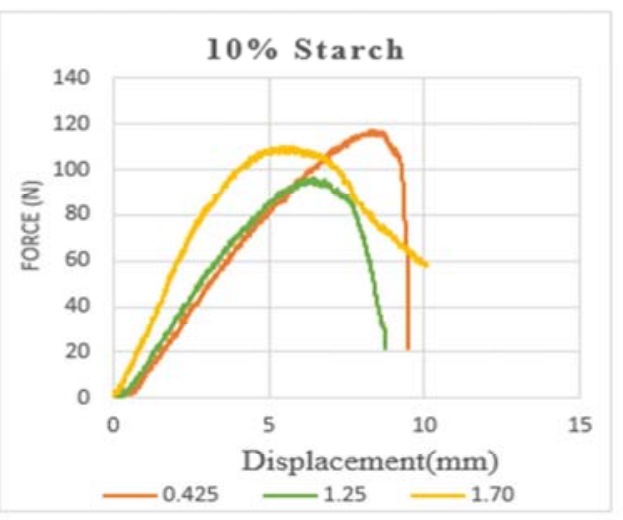

(d)

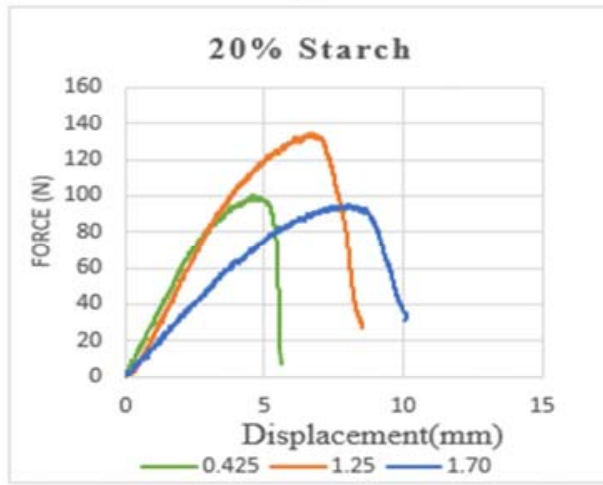

Figure 11. Mechanical bending behaviour as a function of granular class.

\section{Conclusion}

The mechanical characteristics of typha and starch-based insulation boards have been determined. The bending modulus of elasticity MEF, the bending Modulus of Rupture (MOR, the maximum bending deformation $\mathrm{Y}$ and the force-displacement behaviour of the insulation boards obtained were evaluated. In summary, the results revealed that:

1) the swelling rate of the investigated materials varies from $61.43 \%$ (L3; $0.25 \mathrm{~mm} ; 20 \%$ starch) to $113.82 \%$ (L7;
$1.70 \mathrm{~mm} ; 10 \% \mathrm{starch})$ in $2 \mathrm{~h}$ and from

2) $79.42 \%(\mathrm{M} 9 ; 0.125 \mathrm{~mm} ; 20 \%$ ) to $133.09 \%$ (M11; 0.425 $\mathrm{mm} ; 10 \%$ starch) in $24 \mathrm{~h}$. This variation describes a sinusoid with a better estimate of the swelling rate for the M9 composite $(20 \% ; 0.125 \mathrm{~mm})$ and a poor estimate for the $\mathrm{L} 7$ composite $(10 \% ; 1.70 \mathrm{~mm})$. These rates are higher than those recommended by the AINSI A 208.1 1999 standard. The use of these panels in dry environments is therefore strongly recommended. Further work will be carried out on possible treatments for use in humid environments. 
3) the Young's modulus of elasticity is an increasing function of the binder content and varies from 1.52 to $2.31 \mathrm{GPa}$ for granular class A $([0 ; 0.425 \mathrm{~mm}])$. For granular class $\mathrm{B}([0.425 \mathrm{~mm}-1.25 \mathrm{~mm}])$, it increases from $1.30 \mathrm{GPa}(0 \%$ binder) to $1.50 \mathrm{GPa}(10 \%$ binder $)$. For the $15 \%$ starch content, it is evaluated at $1.45 \mathrm{GPa}$ and $1.86 \mathrm{GPa}$ for the $20 \%$ binder content. For the granular class of C (] $0.125 \mathrm{~mm} ; 1.70 \mathrm{~mm}])$, the MEF is an increasing function of the binder content from $0 \%$ to $15 \%$. It varies from $0.90 \mathrm{GPa}$ to $1.3 \mathrm{GPa}$. For the $20 \%$ binder content, the modulus is estimated at $1.29 \mathrm{GPa}$.

4) between $15 \%$ and $20 \%$ binder content, the breaking strength of the material (MOR) is a decreasing function of the binder content. It decreases from 16.1 MPa to 12.8 $\mathrm{MPa}$ for granular class $\mathrm{A}$, from $12 \mathrm{MPa}$ to $11.9 \mathrm{MPa}$ for class $\mathrm{B}$ and from $6 \mathrm{MPa}$ to $5.7 \mathrm{MPa}$ for class $\mathrm{C}$. From $0 \%$ to $15 \%$ binder content for granular class $\mathrm{A}$ and from $0 \%$ to $10 \%$ for granular class $\mathrm{B}$, the MOR is an increasing function of the binder content. It varies respectively from $10 \mathrm{MPa}$ to $16.1 \mathrm{MPa}$ and from $7 \mathrm{MPa}$ to $12.1 \mathrm{MPa}$. For granular class $\mathrm{C}$, this breaking strength is a decreasing function of the binder content. It decreases from $8.7 \mathrm{MPa}$ to $5.7 \mathrm{MPa}$.

5) the breaking sag of the typha-starch material is generally low and varies between $8.40 \mathrm{~mm}$ and $13.65 \mathrm{~mm}$. This characteristic of material brittleness is not uniform for the three granular classes depending on the binder content.

6) the mechanical bending behaviour of the material is identical for binder-free formulations, however, for composites, typha particles with a particle size between $0.425 \mathrm{~mm}$ and $1.25 \mathrm{~mm}$ with a binder content of $10 \%$ to $15 \%$ require a higher displacement before breakage when subjected to a load. They are therefore more ductile.

In summary, the mechanical characterization of typha-starch-based insulation boards indicates that the Young's modulus values and the tensile strength of the material meet the 1999 ANSI 208.1 standard. As for the sag at break, these values explain the brittle behaviour of these materials, and whatever the grain size, the presence of starch changes the behaviour of the material by increasing its deformation at break. This presence in the proportions of 10 to $15 \%$ in small particle sizes $(\leq 0.425 \mathrm{~mm})$ helps to increase the material's rigidity and their resistance to material breakage becomes more important. Thus, the formulations M1 (10\% starch; $0.425 \mathrm{~mm})$ and M4 (15\% starch; $0.425 \mathrm{~mm})$ seem to be the compositions with the best mechanical properties.

\section{Declaration of Competing Interest}

The authors declare they have no competing interests.

\section{Acknowledgements}

Our thanks go to Jules T. Assih for his assistance in the flexion test 4-point of typha-starch insulation panels at ITheMM, Reims, France.

\section{References}

[1] Hounkpatin H. W., Victorin K. V., Sèmassou G. C., Dirk R. N., and Kounouhewa B., (2018a). Simulation of the Thermal Behavior of Various Local Roofings for a Residential House in the Humid Tropics. Advances in Research, 15 (4): 1-15, 2018; Article no. AIR. 42065.

[2] Hounkpatin H. W., Kounouhewa B., Chégnimonhan K. V., Sèmassou C. and Vianou A., (2018b). Numerical Investigation of the Effects of Insulated Envelopes on Hygrothermal Comfort within Habitats of Southern Benin: Test of a Local Material', Current Journal of Applied Science and Technology, vol31, n6, pp. 1-19.

[3] Osseni S. O. G., (2017) Thermomechanical formulation and characterisation of mortars reinforced with banana trunk fibres. $\mathrm{Ph}$. D. Thesis, Université d'Abomey-Calavi, 146p.

[4] Osseni S. O. G., Apovo B. D., Ahouannou C., Sanya E. A. et Jannot Y., (2016). Caractérisation thermique des mortiers de ciment dopés en fibres de coco par la méthode du plan chaud asymétrique à une mesure de température. Afrique SCIENCE 12 (6) 119-129. ISSN 1813-548X, $\mathrm{http} / / / \mathrm{www}$. afriquescience.info.

[5] Youngquist, J. A., Myers, G. C. and Murmanis, L. L. (1987) Resin Distribution in Hardboard: Evaluated by Internal Bond Strength and Fluorescence Microscopy. Wood and Fiber Science, 19, 215-224.

[6] Youngquist, J. A., English, B. E., Scharmer, R. C., Chow, P. and Shook, S. (1994) Literature Review on Use of Nonwood Plant Fibers for Building Materials and Panels. US Government Printing Office, $146 \mathrm{p}$.

[7] Onuorah E. O., Nnabuife E. C., Nwabanne J. T., (2014). Potentials of Bambusa vulgaris Grown in Southeast Nigeria for the Manufacture of Wood-Cement Composite Panels. Journal of Minerals and Materials Characterization and Engineering, Vol. 2 No. 5.

[8] Nenonene A. Y., Koba K., Sanda K., Rigal L., (2014). Composition chimique et propriétés adhésives d'extraits d'organes tannifères de quelques plantes du Togo pour l'agglomération de particules de tige de kénaf (Hibiscus cannabinus L.). Journal de la Société Ouest-Africaine de Chimie J. Soc. Ouest-Afr. Chim., 037: 49- 55 19ème Année.

[9] Soulama S., Atcholi K. E, Naon B., Kadja K., Sanda K.. (2015). Optimization of the Implementation Process and Physical Properties of Cotton (Gossipium hirsutum) and Kenaf (Hibiscus cannabinus L.) Wooden Chipboard. Engineering, 2015, 7, 803-815.

[10] Soviwadan Drovou and Assogba Kassegne K., (2015). Élaboration et caractérisation mécanique et physique des panneaux de particules de sciure de kapokier avec la poudre tanifère de la cosse de gousse de néré. European Scientific Journal, vol. 11, No. 6 ISSN: 1857-7881.

[11] Hounkpatin H. W., Chégnimonhan V. K., Allognon-Houessou E., Kounouhewa B. B. (2020). Thermal insulation panel based on vegetable typha domengensis and Starch: Formulation and chemical characterization. International Journal of Sustainable and Green Energy, 8 (2): 29-37. 
[12] Robertson J. A., de Monredon F. D., Dysseler P., Guillon F., Amado R. and Thibault J. F. 2000. Hydration Properties of Dietary Fibre and Resistant Starch: a European Collaborative Study. Lebensm.-Wiss. u.-Technol., 33: 72-79.

[13] Denarié E., Brühwiler E., Oesterlee C., Redaelli D., Suter R., (2015). Essais de caractérisation - réponse en traction. Acte de la 2ème journée d'étude du 22 octobre 2015: Béton fibré ultra-performant-Concevoir, dimensionner, construire, 25-36, Switzerland, Haute école d'ingénierie et d'architecture Fribourg und Berner Fachhochschule.

[14] Drovou S., Assogba K. K., Sanda K., (2015). Elaboration et caractérisation mécanique et physique des panneaux de particules de sciure de kapokier avec la poudre tanifère de la cosse de gousse de néré. European Scientific Journal. vol. 11, pp 57-69.

[15] Soulama S., (2014). Caractérisation mécanique et thermique de biocomposites à matrice polystyrène recyclé renforcée par des coques de cotonnier (Gossypium hirsutum L.), ou de particules de bois de kénaf (Hibiscus Cannabinus L.)". Thèse Sciences pour l'ingénieur (Génie Mécanique). Belfort - Montbéliard: Université de Technologie de Belfort - Montbéliard.

[16] Kord B., Zare H., Hosseinzadeh A., (2016). Evaluation of the mechanical and physical properties of particleboard manufactured from Canola (Brassica napus) STRAWS. Maderas. Ciencia y tecnología 18 (1): 9-18.

[17] Misnon, M. I., Islam, M. M., Epaarachchi, J. A. and Lau, K. T. (2014). Potentiality of Utilising Natural Textile Materials for Engineering Composites Applications. Materials and Design, 59, 359-368. http://dx.doi.org/10.1016/j.matdes.2014.03.022.

[18] Niang I., (2018). Contribution à la certification des Bâtiments durables au Sénégal: Cas d'étude des matériaux de construction biosources à base de typha, Thèse de doctorat, Université de Thiès, Sénégal.

[19] Beaudoin M., (1976). Essai d'auto-agglomération à sec des particules de bois. Thèse de maîtrise de l'Université Laval. Département des sciences du bois. 93 p.

[20] Oksman et Clemons, (1998). Mechanical Properties of Impact Modified Polypropylene Wood Flour Composites. Journal of Applied Polymer Science. 67 (9): 1503-1513.

[21] Li M., Khelifa M., El Ganaoui M. (2017). Mechanical characterization of concrete containing wood shavings as aggregates, International Journal of Sustainable Built Environment. 6, 587-596.

[22] Sangamesh R., Kumar N., Ravishankar K. S. and Kulkarni S. M., (2018). Mechanical Characterization and Finite Element Analysis of Jute-Epoxy Composite. MATEC Web of Conferences 144, 02014.

[23] Laminates I. G.-M., Caminero M. A., Rodríguez G. P. and López-Cela J. J., (2019). Effect of Thermal Ageing on the Impact Damage Resistance and Tolerance of Carbon-Fibre-Reinforced Epoxy. Polymers, 11, 160, pp 1-15. doi: 10.3390/polym11010160.

[24] Eneyw G. and Negash A., (2019). Study on the Mechanical Characterization of Composite Materials for Automotive Wheel Application. J Material Sci Eng 8: 548, pp 1-4.

[25] Nenonene A. Y., (2009). Elaboration et caractérisation mécanique de panneaux de particules de tige de kénaf et de bioadhésifs à base de colle d'os, de tannin ou de mucilage", Thèse de doctorat, Université de Toulouse, France, 2009. 